Clemson University

TigerPrints

Publications

Teaching \& Learning

$2-2014$

Kinesthetic Investigations in the Physics Classroom

Brooke A. Whitworth

Jennifer L. Chiu

Randy L. Bell

Follow this and additional works at: https://tigerprints.clemson.edu/teach_learn_pub

Part of the Science and Mathematics Education Commons 


\section{Kinesthetic Investigations in the Physics Classroom}

Brooke A. Whitworth and Jennifer L. Chiu, University of Virginia, Charlottesville, VA

Randy L. Bell, Oregon State University, Corvallis, OR

( reating investigations that allow students to see physics in their everyday world and to be kinesthetically active outside of the traditional physics classroom can be incredibly engaging and effective. The investigations we developed were inquiry investigations in which students engaged in concrete experiences before we discussed the abstract concepts and derived the mathematical relationships. ${ }^{1}$ In this article, we describe the approach to inquiry used and an explanation of kinesthetic investigations in general. We then provide a description of several of the investigations and some examples of how students responded to them.

\section{Inquiry and scientific practices}

Inquiry can be defined practically as "an active learning process in which students answer research questions through data analysis." 2 This simple definition of inquiry is based on the National Science Educational Standards and is easy for teachers to understand. The National Research Council (NRC) identifies the scientific practices that support inquiry and that students should be engaged in, including: question generation, experimental design, data analysis, creating explanations, argumentation, and communicating results. ${ }^{3}$ The investigations created encourage inquiry and require students to develop their scientific practices skills.

\section{Kinesthetic investigations}

There are multiple modalities to learn material, including auditory, visual, and kinesthetic. A kinesthetic modality is learning by doing, touching or feeling, and engaging in hands-on activities to develop understanding. ${ }^{4}$ The physics curriculum presents a unique opportunity for teachers to integrate kinesthetic investigations and activities for these learners and to integrate this modality into their teaching. Much of the mechanics curriculum can be applied to experiences in students' everyday lives. We have created kinesthetic investigations for many units of study in an introductory physics course.

\section{Examples from the classroom}

A sampling of the investigations we developed is discussed in detail below. Others included: a Metronome Activity, Physics Olympics, a Graph Matching Lab, a Normal Force Activity, an Introduction to Collisions Activity, an Impulse-Momentum Activity, a Pogo Stick Lab, a Power Lab, and a Slinky Lab. The length of the activities varied, but the ones discussed here occurred over one to two 90-minute class periods. In the majority of the investigations, students begin by observing a phenomenon, using these observations to create hypotheses, and then developing their own questions for investigation.
Students then collect data to answer their questions, analyze the data, and share their results in three to five minutes with the rest of the class. During the sharing of results, students discuss whether their data supported their hypotheses and begin to communicate their own explanations for why or why not their hypotheses were supported. Students record this information in either a handout provided to them or in a lab notebook.

\section{Human pendulums}

The objective of this lab is for students to determine whether the period of a pendulum depends on different properties of a pendulum (Fig. 1). Students begin by observing a simple pendulum, making observations, and brainstorming what factors are measurable and may be affecting the period of a pendulum. Students then develop their own questions for investigation and create hypotheses for the questions they develop. They then collect data, using rope swings hung from the ceiling in the classroom and themselves as the bob of the pendulum. Depending on their question, students measure and record the length of the pendulum using a measuring tape, record the angle of the pendulum using protractors, time the period using stopwatches, and measure the mass of the "bob" using bathroom scales.

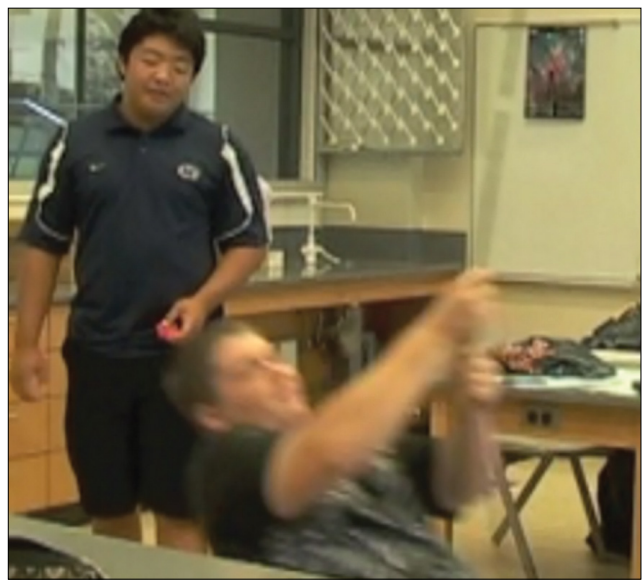

Fig. 1. Students swinging in Human Pendulum Lab.

This lab requires you to be able to hang significant masses (1000-2000 pounds) from the ceiling safely. In our classrooms, we had steel strut systems installed that allowed up to 3000 pounds to be hung from the ceiling. If this is not possible, other options might be the use of swings or constructing your own rope swings from a pull-up bar or trees. In doing this lab, it is important for students to think about how they will control for various variables when completing multiple trials (i.e., how far back students will move before swinging, any stretch in the rope when they sit on the swing). 


\section{Skateboard Lab}

Students begin this lab by observing a ball rolling down an inclined plane. Students again make observations and identify the measurable variables. The objective of this lab is for students to recognize the relationship between position, velocity, and time when an object is accelerating. Students write predictions for what they think the relationship will be between position and time and velocity and time. Students then head outside to a slightly sloped hill with a skateboard, a 50-meter outdoor measuring tape (often available in your PE office), and stopwatches. The measuring tape is laid on the hill and students with stopwatches pick different positions along the hill. One student sits on the skateboard and rolls down the hill. The other students start their stopwatches when the skateboarder starts and stop their watch when he or she passes their position. These times are then recorded for each trial. The data are then analyzed by creating a positionversus-time graph and then a velocity-versus-time graph. Depending on the level of your student and the availability of computers, these graphs can be created using a computer program like Excel or Logger Pro, or the graphs can be created by hand.

When doing this lab, we doubled our lab groups to five or six people so that there would be enough time points recorded for each trial. It is critical when doing this lab to make sure the slope of the hill is slight, that students wear helmets, and that they have a safe way of stopping. Teachers may choose to tape barbells or medicine balls to the skateboards instead of having students sitting on them if these safety considerations cannot be met. If skateboards are not available, using carts or scooters are other options.

\section{Human projectiles}

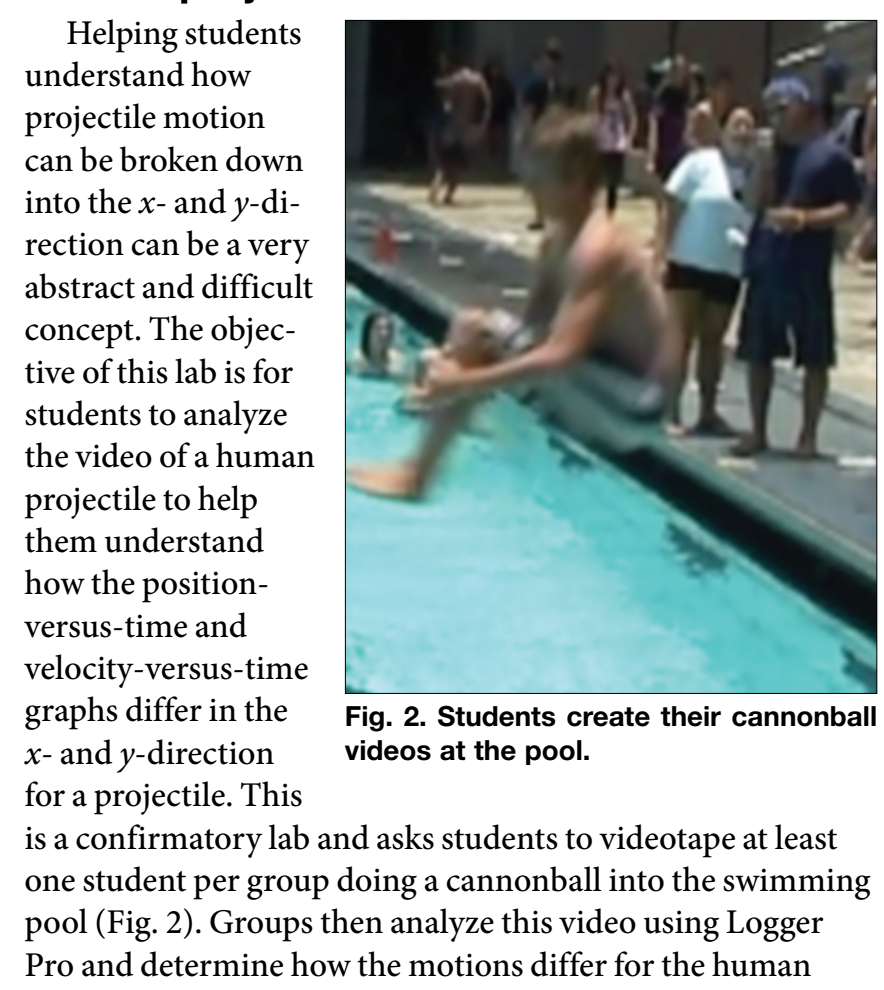

projectile. When doing this activity, it is important to make sure you have a certified lifeguard on duty to ensure the safety of students at the pool. If doing cannonballs into a pool is not possible, using video of other projectiles from the Internet is another option to help students visualize how these motions differ. One possible issue in conducting this lab is importing the files quickly and easily to Logger Pro. It is important to run through this process and make sure you have the right type of video file and camera connections prior to doing the lab.

\section{Running football routes}

In this structured activity students run football routes and throw footballs in order to gain experience with vectors and resultant vectors (Fig. 3). The student running the route is given specific directions, for example: run five meters straight out from the quarterback, turn $90^{\circ}$, and run five meters toward the sidelines. The runner executes the route and the quarterback throws the football to the student at the end of the route. The football's path represents the resultant vector. Students diagram the runner's route and the football's path, and they measure the football's path from the quarterback to the runner. Students then use their evidence and prior knowledge to develop a method for calculating the resultant vector. As a class, we then discuss these methods and determine how we as a class are going to calculate resultant vectors. Depending on your student interests and/or your equipment availability, you could change this activity to use soccer balls, baseballs, etc.

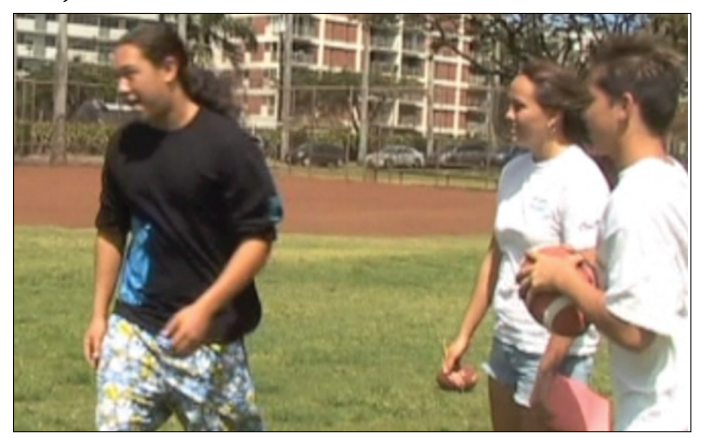

Fig. 3. One group prepares to run a route and throw the football.

\section{Slip 'N Slide ${ }^{\mathrm{TM}}$ friction}

The objective in this lab is for students to calculate the coefficient of friction for three different surfaces: a Slip ' $N$ Slide ${ }^{\mathrm{TM}}$ with no water, with water, and with water and soap (Fig. 4). Students begin by observing how an object's motion can be affected by friction and how different surfaces may affect an object's motion in different ways. Students are then provided a procedure for testing how different surfaces affect friction using a Slip 'N Slide. Each group should have a slider, distance measurer, and timer. An outdoor measuring tape is laid down next to the Slip 'N Slide and each group is instructed to think about how they will control for other variables (i.e., starting location, having a running start or standing start, where on the student to measure the distance, 


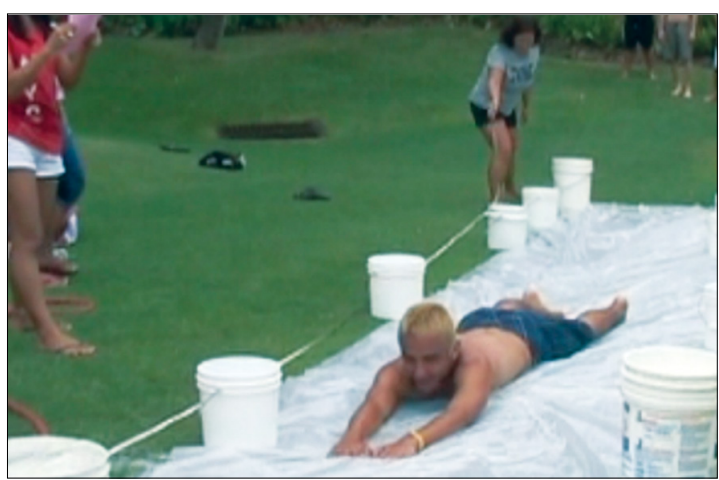

Fig. 4. A student completes his slide with water for the Slip 'N Slide Friction Lab.

etc.). Students assigned the slider role then slide without water, with water, and with water and soap. We used a very slick tarp as our Slip ' $\mathrm{N}$ Slide, so there were no safety issues with sliding without water; however, depending on the type of tarp you use it may be wise to have the sliders wear $t$-shirts to protect their stomachs as they slide or slide on their bottoms. The timer records the time of the slide, and the distance measurer records the distance of the slide. These data are then used with the slider's mass to calculate the coefficient of friction for each surface.

Heading outside to collect the data for this lab is very exciting; however, it is important for students to be safe at all times and expectations for behavior to be discussed prior to leaving the classroom. Depending on your student population, it may be wise to have other adults supervising with you. It is important to make sure your Slip 'N Slide is set up in a flat area, free of any items students could hit when sliding, and with a safe way for students to stop sliding.

\section{Student responses to these investigations}

When implementing these investigations, students were highly engaged in the activities. Students seemed to understand the material and were able to transfer their learning to new situations more easily. This was evident in improvements in course work and on end-of-unit tests. One student made the following comment when asked if she was able to learn the material in the kinesthetic investigations:

"Yes, because it gives me a chance to move around and keeps me thinking and involved in the class. Sitting/ lectures that are too long make it hard to learn and stay focused and absorb information. By acting out/ doing the physics it also helps visualize and see exactly how it happens and why (as opposed to just looking at equations on the board and taking notes) and so it actually makes sense."

Another student commented, "Yes, they make learning the Units in Physics a lot more fun and bring physics into real-life examples, which I feel helps me to understand the ideas and concepts more clearly." These comments were representative of how students responded to the kinesthetic investigations in the physics course. Students were excited and engaged in their learning, they felt they were able to remember the concepts more clearly, and they reflected on these investigations when they were working on tests or other homework problems.

When asked if students were able to understand the concepts behind the kinesthetic investigations, one student responded:

"Yes, the kinesthetic investigations make the concepts very straightforward and easy to understand. They actually make the course relevant to the student because we learn that the things we do in our daily lives have to do with our subject."

Students seemed to grasp easily how the kinesthetic investigations were related to their everyday lives. The more we can engage our introductory physics students in these types of kinesthetic investigations and activities, the more excited they are going to become about the subject. The inclusion of these investigations in the course also resulted in improved scores on end-of-unit tests and what appeared to be a deeper understanding of the content.

\section{Concluding thoughts}

The old Chinese proverb seems most appropriate here: "I hear, I forget. I see, I remember. I do, I understand." Laws cited this proverb as the guiding motto for the Workshop Physics course ${ }^{5}$ she designed for students to become active constructors of their own learning. Her vision for how physics courses could and should be designed aligns with inquiry and scientific practices and the incorporation of other types of learning modalities. This design is what we still are in search of, and the implementation of kinesthetic investigations is one way to involve students in their own learning. Recently, Chris Chiaverina advocated for the physics class to be taken into the world. ${ }^{6}$ The activities described here take physics not only out into the world, but also ask students to be physically and actively engaged in their own learning. Students are excited about coming to class to see what happens next, they see physics in their everyday lives, and they remember their experiences with clarity and depth. Kinesthetic investigations should be a part of every introductory physics classroom.

\section{References}

1. This work was funded by a Curriculum Summer Fellowship awarded by Punahou School.

2. R. Bell, L. Smetana, and I. Binns, "Simplifying inquiry instruction: Assessing the inquiry level of classroom activities," Sci. Teach. 72(7), 30-33 (2005).

3. National Research Council, A Framework for K-12 Science Education: Practices, Crosscutting Concepts, and Core Ideas (The National Academies Press, Washington, D.C., 2012).

4. C. Kanar, The Confident Student (Houghton Mifflin Company, Boston, 1995).

5. P. Laws, "Workshop Physics: Learning introductory physics by doing it," Change 23, 20-27 (July-Aug., 1991).

6. C. Chiaverina, "Taking physics class into the world," Phys. Teach. 50, 572-573 (Dec. 2012).

Brooke Whitworth, University of Virginia, Charlottesville, VA 22903; baw3tj@virginia.edu 